TRAMES, 2010, 14(64/59), 4, 394-410

\title{
TIME IN SPATIAL METALANGUAGE: THE AMBIGUOUS POSITION OF TIME IN CONCEPTS OF SOCIOCULTURAL, SOCIAL AND CULTURAL SPACE
}

\author{
Tiit Remm
}

University of Tartu

\begin{abstract}
In this paper I discuss the problematic presence of time in the spatial metalanguage of cultural and social research. General use of everyday spatial metaphors, as well as attempts to formalise spatial models, explicate the role of space as a modelling system. At the same time, the aspect of temporality is positioned into an ambiguous role as being partly subordinated and rejected from these descriptive models with universalistic intentions. The problematic presence of time and temporality in the spatial metalanguage of cultural and social research is here discussed in the context of three theoretical models of space: Pitirim A. Sorokin's sociocultural space, Pierre Bourdieu's social space, and Juri Lotman's cultural space. Relating to the history of theory through these three models, the discussion suggests a critical account on the ways temporality is presented in the spatial metalanguage. Nevertheless, in combination, these models suggest a possibility to involve multiple socioculturally specific accounts on time into coherent spatial models through the recognition of reflective activity of agents.
\end{abstract}

Keywords: time, spatial metalanguage, sociocultural space, social space, cultural space, Sorokin, Bourdieu, Lotman

DOI: $10.3176 /$ tr.2010.4.07

\section{Introduction}

The organisation of society and culture in time and space, as well as culture specific interpretations of time and space form a frequent field of study. In addition, as means of describing society (by itself and from outside), time and space are modelling phenomena - generating, mediating, and applying the knowledge about the world. Spatial metalanguage with its specific organising nature is among these descriptions. Even though spatial notions have often been used as everyday metaphors rather than fine-tuned concepts, there remain a number of works, in 
which these notions occupy a central role in analysis and in the construction of theoretical models. The dominant role of spatial metalanguage raises the question of the role of time and temporality in relation to it. This becomes even more distinct in the case of formalisation of spatial metalanguage and models, implying thus the general need to be aware and precise in analytical conceptualisations.

This problematic presence of time in 'spatial mode of thinking' is here discussed in three concepts: Pitirim Sorokin's idea of sociocultural space (Sorokin 1964), Pierre Bourdieu's social space (Bourdieu 1984), and Juri M. Lotman's idea(s) of cultural space (Lotman 1975, 2005). Time, assumingly having potential as modelling phenomena similar to space, is not easily graspable in these spatial models with universalistic ambitions. The presence of time and temporality is instead ambiguous, multiple or even rejected - and presumed to be described in another, temporal description. At the same time, all of those three concepts of space are significantly concerned with dynamics of culture and society.

While the discussion here is essentially about critical review of some historical models in theories of culture and society, the concern about clarity of metalanguage and meaning generation in it is wider and persistent. Ideas of each of these major figures of the 20th century social and cultural theory, Sorokin, Bourdieu, and Lotman, have been frequently applied - Sorokin and essentially his notion of social mobility in sociology, Bourdieu in cultural sociological research, and Lotman in semiotics of culture. Despite their different settings, they have each made proposals of general spatial models as a means of describing the social and cultural organisation and dynamics. Each of these spaces is characterised by an emphasis on the cultural aspect of society, and by the idea that systems of meanings can be described in spatial terms, and, essential for the present context, by the dynamics of meaning generation as temporal aspect of this spatiality. Nevertheless, the model of space is different and so is time in each case.

In addition to this spatiality and temporality, descriptors sociocultural, social, and cultural link these three space concepts to the field of research of sociocultural phenomena and posit their role as bridging social and cultural qualities. Each of these notions of space carries with it its own historical context and possible directions for thought. The use of the term sociocultural, for example, implies an essential ambition to combine objects and paradigms into a universally coherent whole, while keeping in mind the mental and material environment and practical outcomes of related research activities. Approaches identifying with this term, or described through it retrospectively, might therefore be considered as forerunners of current views on transdisciplinarity. The account is specifically supported by constructing the sociocultural research object as a complex and multiparametric entity on the one hand, and an endeavour to link knowledge from diverse disciplines through a common metalanguage that merges social and cultural aspects and different disciplinary views on these. This move towards logical order and universality (a hope for integralistic sociology in Sorokin's words) reveals an interesting homology between the terms sociocultural and space 
- as conceptual tools which offer scope for unity and generalisability, on the level of descriptions in the case of space and on the level of secondary descriptions in the case of sociocultural.

\section{Sociocultural space, social space, and cultural space}

What is the role and position of time in relation with primarily spatial models like sociocultural space, social space, and cultural space? Is there sociocultural, social, and cultural time respectively? What are the objects of these descriptive models? These are just some questions that help to understand the ambiguous nature of time in widely spread spatial metalanguage.

The notion of sociocultural space could refer to various conceptual complexes, for example: the materialization of sociocultural systems (e.g. as Keesing (1974) distinguishes the purely ideational cultural system from its realisation in the sociocultural system of, for example, a village layout); physical space as conveying (social and cultural) meanings or as a meaningful system; geographical space with toponyms; space as a metaphor for a logical system of elements and relations; or the perceived environment as spatial and at the same time mediated through social and cultural cognitive means. Additionally, there are notions closely related to sociocultural space besides social space and cultural space. Of particular interest are the terms: sociocultural system (as its object); environment, public space, semiotic or social reality (as analogous notions); and concepts of geographical space such as landscape, place and also network (here understood as a notion shifting the focus of geographical space from physical-spatial to socioeconomic spatial relations). Despite these varied understandings, it appears that many of these closely related expressions do not contradict each other, but rather define a particular viewpoint, aspects in focus or levels of modelling.

Although there cannot be a strictly bounded holistic reference of sociocultural space, it is possible to draw out some tendencies of its involvement in modelling processes and relations. From a broad point of view, these notions can be categorised as either (a) referring to the meaningfulness (and structuration) of the spatial environment; or (b) referring to some system described as 'space'. This paper concentrates on the latter point of view, i.e. space as a modelling tool which often involves the meaningful (physical) environment as its experiential ground and simultaneously as its materialised expression.

This indirect application of space is well explicated in the term social mobility, a notion widely used in sociology. The main academic origin of this term lies in the works of Pitirim A. Sorokin $(1959,1964,2006)$ and his concept sociocultural space. This concept, in its turn, together with notions of sociocultural causality, and time, is presented as a 'reference principle of social science' - i.e. as an approach to metalevel modelling. In addition to the spatial model at the metalevel, Sorokin also exploits the spatiality found at the object level - i.e. in the spatial discourse of describing reality by the respective society itself. Thus sociocultural 
space is not just a scientific referential principle, but is already organising the discourse and worldviews in society at the object level.

\subsection{Sorokin's sociocultural space and its relation to sociocultural time}

Sorokin described his idea of sociocultural space in depth and allotted to it a certain structure. He explains this concept through two aspects: function and structure. Structurally, sociocultural space is described as representing "a specific manifold, consisting of three fundamental planes or aspects: (1) the plane of meanings; (2) of vehicles; and (3) of human agents" (Sorokin 1964:123). This structural description is further developed by analogy with multi-dimensional geometric space, in which the main dimensions are 'language-science-religion-artethics and law' and their sub-divisions giving the specificity required in the case of a society at hand. This multi-dimensional analysis is characteristic of Sorokin. He invokes this model in a discussion on societal crisis using these same main dimensions (Sorokin 1992) and again in a different "five-dimensional universe of psychosocial love" (Sorokin 2002).

The function of sociocultural space, as a referential principle of social science, is to define the position of a certain sociocultural phenomenon in relation to other sociocultural phenomena and to enable the description of different forms of sociocultural change:

Sociocultural space aims to locate the sociocultural phenomena and their components in the sociocultural universe: the component of meanings in the universe of meanings; the component of human agents in the universe of differentiated and stratified universe of human societies; component of the vehicles in the universe of sociocultural phenomena. It is a means of man's orientation in, and adaptation to, the sociocultural universe - the nearest and most important to him, even from the standpoint of a mere survival value (Sorokin 1964:154).

According to Sorokin, when defining the position of meaning, we put an accent on cultural systems, and when positioning human agents, we accentuate their social position (Sorokin 1964:134-135). Thus, the topic of sociocultural space and time can be approached from a cultural perspective, describing the field of meanings of that space and time, and objects in these two categories; or alternatively from the social point of view - using space and time as systems of social positioning and as having specific relations to human agents, their social positions and activities.

A closer look at Sorokin's work reveals the illusion of using a hierarchic triadic model of meaning-subject-object. Sociocultural space is constituted essentially by meanings and their systems. Agents and vehicles are, accordingly, human agents of meanings - "human bearers and agents of a given system or congeries of meanings" - and vehicles of meanings (see Sorokin 1964:130,136). The structure of the respective parts of sociocultural space (systems of agents and vehicles) is organised in the same way as the aspect of meanings: "the sociocultural position of a person is determined through a reference to the same sociocultural system of 
meanings through which the place of a meaning in the universe of meanings is determined" (Sorokin 1964:134). The formal triad thus turns out to be a double dyad characterising the category of meanings as the key aspect of sociocultural space. Relations of meanings with agents and vehicles are organised through parallelism, rather than in mutual triadic relationship. The third potential link, the relationship between agents and vehicles, remains outside the scope of Sorokin's sociocultural space.

Nevertheless, the role of vehicles and meanings appears as more interwoven when viewed in the context of physical space. According to Sorokin (1964:148), physical space has a two-fold relation to sociocultural space. Firstly, physical space is the domain of materiality of the sociocultural system and the bearer of meaning in it. But this material part has its connection to the sociocultural system only through its functioning as a vehicle of meaning. Thus, physical space as a system of vehicles objectifies the system of meanings, and the system of meanings itself makes vehicles socioculturally real, i.e. creates actual cultural objects. Secondly, the material domain conceptualised as physical space is a product of a specific sociocultural milieu or system. While physical vehicles objectify the systems of meanings in the empirical setting of sociocultural reality, conversely, every concept of physical space is sociocultural in its essence. This interrelationship of physical and sociocultural spaces also contextualises the conceptualisation of geographical space as comprising a combination of physical, semiotic and agentive aspects from a spatial point of view.

The question of material space and objects in it is central to Sorokin's efforts to construct a universal reference principle for social science - rejecting all concepts of space from natural science and geometry, whilst simultaneously constructing his 'space' on chosen structural and ideological principles. Although sociocultural space could be a universal descriptive model in and of itself, it also forms a conceptual pair with sociocultural time. Time, for a social (and cultural) researcher, in the context of spatial models could in principle be a feature included in the explication of that space (alongside the discussion of material objects, agents, material space, etc.) or as an equal counterpart or another model of organisation (as two aspects of the logical order of perceived world, as formulated in Piaget 1946).

For Sorokin, sociocultural time as a referential principle of sociology and social science (alongside sociocultural space and sociocultural causality) "conceives and measures sociocultural phenomena - their duration, synchronicity, sequence, and change - in terms of other sociocultural phenomena taken for the point of reference" (Sorokin 1964:171). The main characteristics of sociocultural time are that it is qualitative, having indivisible units that are of social origin; it does not 'flow on evenly' as a mere quantity; it is determined by social conditions, and it reflects the rhythms of the group's social life (Sorokin 1964:197). From here it can be concluded, that sociocultural time is, above all, practical time that creates a reference system for sociocultural phenomena, organising an emic system of time and reflecting and facilitating the rhythms of the society's existence. 
Sorokin gives much attention to culturally different concepts of daily time flow as well as time reckoning and measurement. Nevertheless, his attempt to describe sociocultural time through three planes of time (or types as in typology in relation to the organisational referential aspect of time as topological) - aeternitas, aevum and tempus (Sorokin 1964:215-216) - could be considered conceptually central to his general approach. Sorokin derives this division from the medieval philosophy of time (see e.g. Porro 2001). In his major work "Social and cultural dynamics" (2006) Sorokin links this to his own division of cultures into ideational, idealistic and sensate phases, thus transforming the three planes of time from medieval, primarily theological, categories into sociological ones.

While Sorokin builds a general and static model of sociocultural space, it should not go unnoticed that his "Social and cultural dynamics" is centred on dynamics, discussing the change practices and principal mechanisms of changes over the history of humankind. Although the concept of sociocultural space is a descriptive tool for Sorokin at that point, the distinctions between ideational, idealistic and sensate phases of development are analogously expressed in his conceptualisations of time and practices related to time. From this linkage between historiosophic phases and categories of referential principles of social sciences follows a particular significance of his distinctions between types of sociocultural time, tempus, aevum, and aeternitas as notions of time, age and eternity.

While tempus includes the phenomena of movement, change 'flow of time' and the reckoning and measuring of time; aeternitas and aevum help locate sociocultural phenomena that seem to be outside of daily and empirical understanding of time (like meanings and validities as being actualised in time but not temporally bound). Thus, we can conclude from Sorokin that sociocultural space locates and organises sociocultural objects statically to enable the study of sociocultural change by comparing different states of the system over a period of 'external time'. Sociocultural time on the other hand enables the study of dynamic aspects integrated to these states of tempus, aeterntias and aevum: conceptualised as modes of change and relation within society's own relational temporal organisation.

Sorokin's approach could provide an opportunity for a holistic (integralistic according to Sorokin) view on sociocultural phenomena and space. However, one of the main reservations here would be the notion of sociocultural space itself. Using expressions such as "What is your position towards war?" as argumentation, Sorokin builds his general descriptive meta-level model on one aspect of the object level discourse, namely the (metaphorically) spatial expressions that we can find in everyday discourse. Even though Sorokin himself claims that sociocultural space should not be understood as a metaphor, it could be claimed that he separates the widespread metaphor of space as a container (Lakoff and Johnson 2003) from its basis in experience of the physical environment and applies the term to another category, meanings in society, with its own objects and dimensions.

Even though spatial models are widespread in languages and thought, this is just one possible model. A problem is whether the characteristics of the applied 
model are explicit enough to overcome connotations from the metaphor itself. By the mediation of an abstract model that uses everyday spatial metaphors, Sorokin tends to present these concepts not just as descriptive tools but as principles of reality itself. Thus, we end up in a verbally confusing situation in which sociocultural space is not spatial in the ordinary sense; spatiality is a concept in the sociocultural system and is simultaneously conditioned by it; the ordinary understanding of space (used in everyday language and on which, it can be claimed, Sorokin builds his notion of sociocultural space) turns out to be secondary - based on sociocultural space and its abstract spatiality. To avoid confusion and abuse of the term space, one might talk about existing sociocultural systems (or the sociocultural universe, as Sorokin occasionally does) that can be described by the model of sociocultural space. Whether the notion of spatiality is understood as a metaphoric or abstract notion per se does not then influence reality but remains on the level of construction of descriptive language.

At the same time, the everyday understanding of time can be seen to be more directly conditioning the concept of sociocultural time. Quantitative time, which Sorokin so forcefully opposes, is an important part and even the basis of the tempus plane of sociocultural time. The tempus plane is largely a conglomerate of diverse methods of time reckoning, the emic aspect of sociocultural time. Thus, Sorokin's sociocultural time is, above all, 'socioculturally specific time' with its group (culture-) specific units, measurement techniques, and attached values at the object level; while space could be understood as a metaphor belonging to the spatial metalanguage.

\subsection{Bourdieu's social space, and its time}

Social space for Pierre Bourdieu is essentially a relational space, a space of positions defined in relation to one another. In his discussion on 'social space and genesis of groups', he explains,

Initially, sociology presents itself as a social topology. Thus, the social world can be represented as a space (with several dimensions) constructed on the basis of principles of differentiation or distribution constituted by the set of properties active within the social universe in question, i.e., capable of conferring strength, power within that universe, on their holder. Agents and groups of agents are thus defined by their relative positions within that space. [---]. Inasmuch as the properties selected to construct this space are active properties, one can also describe it as a field of forces, i.e., as a set of objective power relations that impose themselves on all who enter the field and that are irreducible to the intentions of the individual agents or even to the direct interactions among the agents (Bourdieu 1985:723-724).

These features, like objective power relations, multidimensional organisation, the role of agents in activating and subordinated to properties, characterise social space as an objective but dynamic and relational complex of social relations, agents, and objects. Being a specifically organised spatial model, Bourdieu's concept of social space foregrounds specific temporal aspects of social phenomena 
and their organisation. Understanding aspects relating social space to its time and both of these to the objects they model, would benefit from discussion.

Bourdieu describes the general structure of social space as comprising three dimensions. These dimensions are defined by "the volume of capital, composition of capital, and change in these two properties over time (manifested by past and potential trajectory in social space)" (Bourdieu 1984:114). The general working principles of social space, as Bourdieu depicts this, are to be found in two key notions: first, the notion of field, as derived from the metaphor of the battle field as a dynamic and exclusive system of positions, dispositions and contesting forces; and second, the notion of habitus that enables the involvement of human agents and practices as observables. Habitus and potential trajectories are thus two concepts which open up a specific field of temporality in Bourdieu's theory.

While social space is an analytically abstracted model of practical space (or 'actually lived relations'), it is at the same time also an objective space (as 'spatially' organised relations) for agents who contemplate it and have the will to transform or conserve it. Through reflective discourse, agents can be said to form a kind of inner metalevel of social space. However, an agent is here primarily 'a point in social space', a point of view, a perspective defined by its objective position in that space. Social space again is, for that agent, the first and last reality and thus determines the agent's perspective to the social space itself (Bourdieu 1994:28-29). This 'ping-pong' of determination includes a potential for the emergence of reflective agent. This potential reflectivity is a feature that enables a close link between Bourdieu's notion of social space and Lotman's cultural space as largely derived from cultural (self-)descriptions.

Although the idea of point of view and the ability to reflect on one's own social space might suggest an opposite intention, what interests Bourdieu is not so much the space in discourses (even though his models are applicable also to that), but rather the relational space of practices. Practices have their place in social space through habitus as a set of preferences realised in practices and possessions which define and follow on from the position of the agent in social space. This position is not a ranking (hierarchical) position but rather one of relational situatedness in social space. It is important to note that habitus creates practices which can be classified and, at the same time, classifies them. The latter also includes the creation of the system(s) of classification.

Agents, their practices, geographical location and their possessions become significant only through their relational meaning, i.e. a pure difference that is recognized in classifying practices. Thus, objects as possessions become part of social space primarily as distinctive features of agents:

The objects are not there to fulfil a technical or even aesthetic function, but quite simply to symbolize that function and to solemnize it by their age, to which their patina bears witness. Being defined as the instruments of a ritual, they are never questioned as to their function or convenience. They are part of the 'taken for granted' necessity to which their users must adapt themselves (1984:313). 
As suggested by Bourdieu, physical space is also involved in social space as a distinction-making resource which supports social identity, instantiates social distance, and enables encounters of people with distant positions in 'anomalous' geographical places. Urban public space would be one example of this kind of space where separate trajectories of people might cross. Whether the other is recognised at this encounter and how, is the question of meaning generation through recognised differences. Thus, those places of encounters of subjects, are not any neutral physical space but rather a highly semiotised geographical space that supports the social distance and distinctions through physical distance. This geographical space is also managed as a means of maintaining or changing the social space through changes in the accumulation or reassessment of capital.

This change of social relations over time and the management of change forms a temporal dimension that is already embedded in social space. Above all, social space for Bourdieu is historical, an outcome of specific changes and states of fields. In the structural sense, historical time is a dimension of social space which describes changes in the volume and composition of capital over time in terms of past and potential trajectories projected to the future. Thus, time is an external condition of social space made manifest in that space through the recognition of the historicity of capital, objects, and habitus. The subject learns and embodies habitus through interaction with the social surroundings. The subject or agent also changes position (i.e. of social mobility in multiple dimensions) whilst the system of positions and dispositions is simultaneously changing too. Thus the context of the agent in that space changes even if personal practices are sustained by the agent. Additionally, positions and dispositions have their own trajectories of development - past and future - which the agent realising the position is supposed to follow. At this point we can see that the determination of specific 'normal' developments can be included into social space as a kind of reflective tendency of habitus to organise the world 'to be normal'. Thus, there is an inherent 'normalising' temporality in habitus and also in social space.

Even though time is an essential factor in Bourdieu's thinking, his use of time is, here, mainly that of external, chronological time of a type which does not depend on the social space in question or the views of the agents located in that social space. One area, in Bourdieu's concept of social space, in which multiple experiences and conceptualisations of (context specific) time (and space) may generate tension, is in the struggle over classifications as a form of the more general struggle of fields. The possibility that each opposing field and subfield might have its own understanding of time and space is closely related to differences in judgements of historicity as a value and the emphasis put on this. Interpretations of the accumulation of time in objects, and interpretations of the historicity as the accumulation of time which legitimises authority, are crucially dependent on the reflective habitus. Nevertheless, the reflective habitus is not directly included into social space by Bourdieu, nor is it discussed by him at length. A possible reason for this could be that these interpretative aspects of time 
are scarcely measurable even in relativistic models and thus remain outside the sociological approach within which Bourdieu is discussing social space.

\subsection{Cultural space as the semiotic space of culture, Lotman}

While the concepts sociocultural space and social space as descriptive models can be traced to some specific definition, the concept of cultural space tends to retain specific vagueness in present discussion, as well as in general usage since the term lacks a uniformly accepted definition. Also in academic contexts, the term cultural space may often be interpreted as belonging primarily to the sphere of everyday language. One of the more common uses expresses the idea of national cultural space and the travel of ideas, texts, objects and persons between them: e.g. Estonian cultural space, Russian cultural space, the Estonian and Russian cultural space in Estonia etc. While such a space forms the circulation environment of texts of culture, it also foregrounds national and institutional boundaries. Even though the nature and location of the boundary of cultural space often remains unspecified, these aspects are crucial for an understanding of the nature of the entity.

Theoretical treatments of this concept of cultural space often refer to the work of Juri M. Lotman, albeit somewhat paradoxically. However, the expression 'cultural space' is relatively rare in Lotman's work and, and when it is explicit, is often not distinguished from its general everyday meanings. At the same time, the semiotics of culture developed by Lotman and his colleagues in the Tartu-Moscow school of semiotics can be characterised as following a spatial logic of thought (Nöth 2006, Randviir 2007) and spatial metalanguage (e.g. notions like the space of the text, textual space, semiotic space, centre and periphery etc.). In this context it might be more appropriate to talk about the network of texts and boundaries as "the semiotic space of culture only where semiotic processes are possible" (Lotman 1986:6).

Although the cultural space as a simultaneous conglomeration of various texts and boundaries would be a phenomenon of the object level, its spatiality relates to the level of cultural description at the metalevel. In the foreword to Sign Systems Studies XIX, Lotman highlights the importance of space in text:

space in text is a modelling language with the help of which any meaning can be expressed as soon as it acquires the character of structural relations. Therefore, spatial organisation is one of the universal means for the construction of any cultural model (Lotman 1986:4).

Accordingly, cultural space can be considered as a modelling device which works at the object level and which demonstrates the centrality of spatial logic in the self-description of culture. Spatial relations generate (generative side of modelling) the signification and space is used to represent (representative side of modelling) the relations of object level in descriptions.

While cultural space as Lotman conceives it is constituted by a maze of borders and entities (texts), its spatial structure is characterised by the oppositions of centre-periphery, inside-outside, us-them, etc. A remarkable connection to the 
field of topology is actualised here. Topology as a basis for the creation of typologies creates a close connection between the spatiality of culture and typologies of cultures, which is a favourite topic for Lotman. Similarly, the application of topology in the semiotic study of space is also fundamental for Algirdas J. Greimas who attempts to construct semiotics (of space) explicitly based on topological grounds (Greimas 1986). While Greimas is focused on the social aspect, Lotman is focused on topological models of cultural self-descriptions in texts. Whereas topology as the recognition of entities forms a part in all typologies, the dynamic aspect, topological transformations (e.g. Lotman 1979), is at least as decisive for Lotman's use of spatial binary concepts and accordingly for the idea of cultural space as combining static and dynamic aspects of the culture.

For these spatial cultural models with dynamic binary structures, human agents and the material world are presented first of all as texts. Although Lotman studies 'great individuals' characteristic of Romanticism, the being and acting of these agents becomes semiotically textual in the context of the poetics of everyday behaviour (see Lotman 1984). Similarly, materiality is actualized as a bearer of textual structure. Accordingly, action and practices are significant in textual relationships - an act exists as an event as long as it is recognised as a crossing of a border. Normalised neutral actions and activities, e.g. cultural rhetoric, norms, conventions, might not in this sense be recognisable, significant, or actualised in cultural space, and thus may not exist in cultural self-description.

Insofar as cultural space is a space of meanings, the meaning that emerges in difference and opposition is modelled as spatial opposition. Being dynamic by nature, that spatiality does not have a uniform relation to time. As an aggregate of texts and languages, cultural space includes directions and practices for change; one of these mechanisms is self-reflection as future oriented autocommunication, in Lotman's terms. Through self-description (an inner reflection that textualises the culture as its own object) culture incorporates change, makes sense of changes and their temporal conditions; and constructs an 'objective external time' as the order of these changes. At the same time, the spatiality of cultural space is not separate from its temporality, but rather analogous and interchangeable to it. The opposition of categories of space and time is introduced according to the needs of the processes of cultural (self-)description. Accordingly, the beginning and end can be seen as spatial or temporal (or spatio-temporal) categories, and the rhetorical exchange in these oppositions provides a tool with which to create descriptions of reality according to the preferences of the utterer (e.g. see Remm 2009 for an analysis of historical-spatial-causal realities (re)presented through beginnings and ends of cities as entities of cultural space). In comparing these different views and their socio-cultural backgrounds, it is useful to remember Lotman's assertion that any description in culture appears as a self-description on the level of culture as a whole (Lotman 2005, Torop 2005). 


\subsection{Cultural space as an object-space in descriptions, Lotman}

In addition to the notion of cultural space as the semiotic space of a culture, Lotman has also defined cultural space in the specific context of self-descriptional modelling. In the article "On the metalanguage of a typological description of culture", Lotman notes about cultural space: "A boundary divides the cultural space into continuums which contain a point or a set of points" (Lotman 1975:104). This falls into the context of concepts such as cultural texts, types of cultures, cultural models and worldview with its spatiality in this context.

A cultural text is formed by texts (as variants of the cultural text as an invariant) that belong to one cultural type, a notion which, while forming the conceptual ground for Lotman's discussion, remains ambiguously subjective. As an abstract model of reality, the cultural text is a worldview or image of the world that has an 'ambition' to be universal and all-encompassing. At this point, it is important to distinguish two sources of spatiality - the spatial structure of worldview and the spatial models of the metalanguage describing cultural types. Their close connection can be seen as the relation of a text (structure of the worldview) and its metalanguage (spatial models).

The cultural texts can be divided into two subgroups: (1) the texts of static relations characterising the structure of the world, and (2) dynamic texts which describe the disposition and activity of 'man' in the world (Lotman 1975:102103). The association of these two subgroups takes place in cultural themes - an aspect that appears in a later edition of this article (Lotman 1992) but not in the first ones (1975, and its original in Russian in 1969). Hence, space or spatiality is present in object level structures and in models at the metalevel both as a static structure of relations and through the dynamic activities realising these relations. Being characterised by multiple boundaries dividing its internal space, such a space of cultural text is a model of everything - the general and universal order of given culture.

In addition to the spatial structure of the worldview, the models in the typological metalanguage of culture are also spatial - Lotman calls cultural models the descriptions of cultural texts that are created with the spatial (especially topological) methods of modelling. The basic characteristics of cultural models are (1) types of fragmentation of universal space; (2) the dimension of universal space; and (3) orientation (Lotman 1975:104). This brings us once again to the notion of cultural space: "A boundary divides cultural space into continuums which contain a point or a set of points" (Lotman 1975:104). From here, Lotman turns again to cultural models, relating the semantic interpretation of cultural models to the establishment of correspondence between elements of cultural models (space, boundary, points) and phenomena in the objective world.

Thus, cultural space is a cultural object-space given in the description of a cultural model. A cultural model is a spatial model based on a topological approach in the metalanguage for describing the worldview - which is the cultural text as an abstract invariant of texts in the given cultural type. In other words, cultural space is the worldview modelled by a 'spatial thought'. Again, it is to be 
noted that Lotman in this work concentrates on a specific field (which even though a specific field, being a point of view it can still presume to cover everything), namely the models of cultural self-description and modelling the whole universe from the point of view of the given culture. Keeping in mind the distinction between the view from the inside and the view from the outside of culture - so important for the Tartu-Moscow school - the idea of cultural space as a semiotic space of culture and as a model achieve partial overlap:

In investigations of a semiotic-typological nature the concept of culture is perceived as fundamental. In doing so, we should distinguish between the conception of culture from its own point of view and from the point of view of a scientific metasystem which describes it. According to the first position, culture will have the appearance of a certain delimited space which is opposed to the phenomena of human history, experience, or activity lying outside it (Uspenskij et al. 1998:33).

Accordingly, cultural space is a model related to the inner point of view - the models of culture - and not to the metalevel description of the culture and its nonculture as an external reality for the describer.

For Lotman, space does not refer to an abstract universal dimension, but first of all to the surroundings of a unit, a precondition for its work; accordingly, a text is in a textual space, an act of language is in the space of language, a sign is in the semiosphere etc. At the same time, it is remarkable that we can more frequently find the notion of the space of non-culture than the space of culture in Lotman's writings. Here we can follow the reconstructive approach of Tartu-Moscow school that places secondary modelling systems in a primary position and allows the reconstruction of primary modelling systems as its analytical prerequisite. Thus, the primacy of primary modelling system is, contrary to Winfried Nöth's (259) assertion, neither logical nor evolutionary primacy, but rather reconstructive (and descriptional) primacy from the point of view of a text in the secondary modelling system. From the point of view of cultural dynamics, the cultural subject is first opposed to the non-cultural as a spatial elsewhere or there and based on this oppositional spatiality, the modelling of cultural space is possible.

The significance of temporality in Lotman's spatial system appears not so much in the typological comparison over time, but rather in the vision of culture as essentially involving a multitude of change trends and mechanisms, and the interpretations of these. Thus Igor Chernov, giving an historical survey of TartuMoscow school, notes:

In the single mechanism of culture there co-exist semiotic structures with accelerated tempos of development and texts or whole cultures oriented towards immutability and total or partial exclusion from temporal dynamics. There is an obvious connection between these phenomena; and, this makes it necessary to introduce the factors of cultural time and cultural space into a semiotic description (Chernov 1988:15).

In conclusion, cultural space (as the semiotic space of culture) can be seen as coinciding with cultural space (as the object-space presented in a model) applied 
at the metalevel. Thus cultural self-descriptional categories and worldview are transferred from culturally descriptive analytical practices to the typological language for cultural description at the scientific metalevel. In Lotman's case we can see the application of his own cultural typological-topological theoretical apparatus in concepts that present culture and cultural space as semiosphere. The space given in descriptions of cultures (through models with topological metalanguage) is objectified and applied as a neutral model at the level of cultural research. Oppositions of our space and their space or cultural and non-cultural becomes a universal tool of description - cultural space as an analytically descriptive model.

\section{The ambiguous role of time in the spatial modelling of society and culture}

Underlining the reflective character of the spatial models discussed here and the feedback relationship between object- and meta-level, one might claim that highly theoretical and universalistic models of sociocultural, social, and cultural space are legitimating the researcher's general spatial mode of thought - and that they are intended for that legitimating purpose. While social space for Bourdieu is an abstract representation at the metalevel, bringing into analytical simultaneity the positions which agents can never apprehend in their totality and in their multiple relationships, it is at the same time also an objective space for the agents who contemplate on it and have the will to transform or conserve it - as spatially organised relations

[...] agents have points of view on this objective space which depend on their position within it and in which their will to transform or conserve it is often expressed. Thus many of the words which sociology uses to designate the classes it constructs are borrowed from ordinary usage, where they serve to express the (generally polemical) view that one group has of another (Bourdieu 1984:169).

Similarly, sociocultural space for Sorokin is the most actualised environment of the subject; the abstract concept and structure of sociocultural space is partly derived from the spatial expressions used in everyday language through which there is again a possibility for the reflective relation of subjects with that space both as concept and as reality.

While all three spatial concepts discussed here essentially include these aspects of referentiality, their structural ideas have different foundations. Sorokin's sociocultural and Bourdieu's social space both follow the example of geometric (multi-) dimensional space which can, in principle, be projected into twodimensional graphs. Additionally, Bourdieu's concept includes the dynamics between different fields and thus the space is more relational - a relational constitution of relational positions. Lotman's concepts of cultural space are instead based on topological space with the main characteristic of opposition inside-outside. Topology is thus the descriptive language in the context of cultural 
typologies. The result of such mapping is not the objective localisation of social and cultural phenomena, but rather the agglomeration of subjective worldviews or images of the world. Here, and especially in Lotman's original in Russian, the term world image ('kartina mira') is clearly suggesting the use of visual cognitive models in cultural modelling.

A closer look at the concept of a spatial metalanguage reveals the problematic position of time in relation to these models of space. Time is present and even essential in these models, but its usage tends to either be restricted to just one aspect of it (external time) or instead it serves as a mechanism for indeterminacy. The contingent nature of its latter usage does not fit well in the otherwise universalistic model of description. Compared to other characteristics such as the role of agents, objects, and materiality; time, being multiple and over-emphasized, tends to remain an incoherent category, not a part of the model, but rather an addition to the model.

The multifaceted character of time is already problematic for spatial models in recognition of the fact that, in an elementary relationship of describer-modeldescribed, each unit can have its own logic and perspective. In relation to time, each of these may include some relation to some common time measure (e.g. as objective flow), categorization of this external condition, and the subject's own concepts of time. Consequently the spatial models can have their heuristic value in describing changes of social and cultural issues in a historical perspective, but sociocultural, social and cultural time as the interpretation of time and temporality as simultaneously multiple is not well supported by this spatial metalanguage.

While this feature of indeterminacy in the model can be an inconvenience, it is potentially also a chance to overcome the 'trap of spatiality'. Lotman's concept of cultural space discussed here belongs mainly to his works from late 1960s and 1970s on typologies of cultures; remaining close to this typological conceptual apparatus, Lotman moves on to questions of dynamics and the mechanisms of change in culture in his later works. A central example here would be the concept of semiosphere (Lotman 2005) which is nevertheless excluded from the main discussion here as an 'extension' of concept cultural space. Even though the concept of semiosphere clearly belongs to spatial metalanguage, one of its essential virtues is its ability to bring multiple segments from culture's diachrony into simultaneous co-existence in one cultural situation in synchrony. Similarly, the above-mentioned aspect of Bourdieu's theory in which the struggle of fields takes the form of a struggle over classifications - and thus potentially over the views on temporality - deserves a more thorough development. Probably the most extensive model of space here, Sorokin's sociocultural space, includes time as a synchronic system of socially realised meanings. Additionally, however, Sorokin's idea of types of sociocultural time, tempus, aevum, and aeternitas as parallel to the ideational, idealistic and sensate phases of sociocultural development, suggests in principle that there is a potential to analyse temporality from the point of view of society itself, and of relating this field of temporalities to the society as modelled in terms of 'spatial thought'. 


\section{Acknowledgements}

This research was supported by the European Union through the European Regional Development Fund (Center of Excellence CECT).

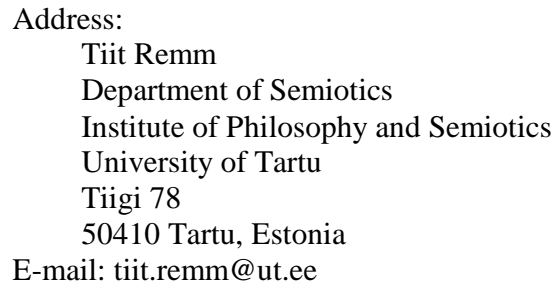

E-mail: tiit.remm@ut.ee

\section{References}

Bourdieu, Pierre (1984) Distinction: a social critique of the taste. Harvard University Press: Cambridge.

Bourdieu, Pierre (1985) "The social space and the genesis of groups". Theory and Society 14, 6, 723-744.

Bourdieu, Pierre (1994) Raisons pratiques: sur la théorie de l'action. Paris: Seuil.

Chernov, Igor (1988) "Historical survey of Tartu-Moscow Semiotic School". In Semiotics of culture. Proceedings of the 25th Symposium of the Tartu-Moscow School of Semiotics, Imatra, Finland, 27th-29th July, 1987, 7-16. Henri Broms and Rebecca Kaufmann, eds. Helsinki: Arator.

Greimas, Algirdas J. (1986) "For a topological semiotics". In The city and the sign: an introduction to urban semiotics, 25-54. Mark Gottdiener and Alexandros Ph. Lagopoulos, eds. New York: Columbia University Press.

Keesing, Roger M. (1974) “Theories of culture”. Annual Review of Anthropology 3, 73-93.

Lakoff, George and Mark Johnson (2003 [1980]) Metaphors we live by. Chicago: University of Chicago Press.

Lotman, Juri M. (1975 [1969]) "On the metalanguage of a typological description of culture". Semiotica 14, 2, 97-123.

Lotman, Jurij M. (1979 [1973]) “The origin of plot in the light of typology". Poetics Today 1, 1-2, $161-184$.

Lotman, Juri (1984 [1977]) “The poetics of everyday behaviour in Russian eighteenth-century culture". In The semiotics of Russian culture, 231-256. Ann Shukman, ed. Ann Arbor: University of Michigan Press.

Lotman, Jurij M. (1986) "Ot redakcii (K probleme prostranstvennoj semiotiki)." Trudy po znakovym sistemam (Tartu) 19, 3-6.

Lotman, Jurij M. (1992 [1969]) "O metajazyke tipologičeskix opisanij kultury". In Jurij M. Lotman, Izbrannye stati $v$ trex tomax, 1. Stati po semiotike i tipologii kultury, 386-406. Tallinn: Aleksandra.

Lotman, Juri M. (2005 [1984]) “On the semiosphere”. Sign Systems Studies 33, 1, 205-229.

Nöth, Winfried (2006) "Yuri Lotman on metaphors and culture as self-referential semiospheres". Semiotica 161, 1-4, 249-263.

Piaget, Jean (1946). Le développement de la notion de temps chez l'enfant. Paris: Presses univ. de France.

Porro, Pasquale ed. (2001) The medieval concept of time: studies on the scholastic debate and its reception in early modern philosophy. Leiden, Boston, and Köln: Brill. 
Randviir, Anti (2007) "On spatiality in Tartu-Moscow cultural semiotics: the semiotic subject". Sign Systems Studies 35, 1-2, 137-159.

Remm, Tiit (2009) “'Alguse' ja "lõpu” kui linna kirjeldamise vahendite kuulumisest linna juurde”. ['The beginning' and 'the end' as descriptive tools and aspects of city.] Acta Semiotica Estica 6, 86-105.

Sorokin, Pitirim A. (1959) Social and cultural mobility. Glencoe: Free Press.

Sorokin, Pitirim A. (1964 [1943]) Socio-cultural causality, space and time: a study of referential principles of sociology and social science. New York: Russel and Russel.

Sorokin, Pitirim A. (1992 [1941]) The crisis of our age. Oxford: Oneworld.

Sorokin, Pitirim A. (2002 [1954]) The ways and power of love: types, factors, and techniques of moral transformation. Philadelphia and London: Templeton Foundation Press.

Sorokin, Pitirim A. (2006 [1957]) Social and cultural dynamics: a study of change in major systems of art, truth, ethics, law, and social relationships. (Revised and abridged in one volume by the author.) New Brunswick and London: Transaction Publishers.

Torop, Peeter (2005) "Semiosphere and/as the research object of semiotics of culture". Sign Systems Studies 33, 1, 159-173.

Uspenskij, B. A., V. V. Ivanov, V. N. Toporov, A. M. Pjatigorskij, and J. M. Lotman (1998 [1973]) Theses on the semiotic study of cultures (as applied to the Slavic texts). Tezisy $k$ cemiotičeskomu izučeniju kultur. Kultuurisemiootika teesid. (Tartu Semiotics Library, 1.) Tartu: University of Tartu. 